\title{
Failure mechanisms and cutting characteristics of brazed single diamond grains
}

\section{Journal Article}

Author(s):

Buhl, Sebastian; Leinenbach, Christian; Spolenak, Ralph; Wegener, Konrad

Publication date:

2013-05

Permanent link:

https://doi.org/10.3929/ethz-b-000058278

Rights / license:

In Copyright - Non-Commercial Use Permitted

Originally published in:

The International Journal of Advanced Manufacturing Technology 66(5-8), https://doi.org/10.1007/s00170-012-4365-z 


\title{
Failure mechanisms and cutting characteristics of brazed single diamond grains
}

\author{
Sebastian Buhl • Christian Leinenbach • \\ Ralph Spolenak • Konrad Wegener
}

Received: 27 January 2012 / Accepted: 28 June 2012 / Published online: 11 July 2012

(C) Springer-Verlag London Limited 2012

\begin{abstract}
The knowledge about the cutting characteristics and the critical loading of brazed diamonds is essential for a safe and economic application of engineered grinding tools. Scratch tests were performed with single grains. The experiments were conducted with standard polyhedral diamond grains of different sizes, ranging from 300 to $850 \mu \mathrm{m}$, brazed with an Ag-Cu-based and a $\mathrm{Cu}-\mathrm{Sn}$-based active filler alloy onto a steel pin. Two failure mechanisms were revealed, namely "grain pullout" and "grain fracture". Large grits mainly fail by grain fracture, whereas the smaller ones were mostly pulled out. This trend is supported by a simple mechanical model. The critical values, i.e. cutting force/scratch area, for grain fracture and grain pullout show a decrease with bigger grit size. Scratches are also analysed in terms of cutting characteristics. The dependency of the cutting and the normal force on the scratch area can be described by a power law with powers ranging between about 0.2 and 0.7 , respectively. The measured cutting forces strongly depend on the rake angle, which was tested for $-19.5^{\circ}$ and $-35.3^{\circ}$.
\end{abstract}

Keywords Brazing $\cdot$ Diamond $\cdot$ Scratch $\cdot$ Failure $\cdot$ Cutting

\author{
S. Buhl $(\bowtie) \cdot K$. Wegener \\ Institute of Machine Tools and Manufacturing, ETH Zurich, \\ Tannenstrasse 3 , \\ 8092 Zurich, Switzerland \\ e-mail: buhl@iwf.mavt.ethz.ch \\ S. Buhl $\cdot$ C. Leinenbach \\ Empa, Swiss Federal Laboratories for Materials Science and \\ Technology, Laboratory for Joining and Interface Technology, \\ Ueberlandstrasse 129, \\ 8600 Duebendorf, Switzerland \\ R. Spolenak \\ Laboratory for Nanometallurgy, ETH Zurich, \\ Wolfgang-Pauli-Strasse 10, \\ 8093 Zurich, Switzerland
}

\section{Introduction}

In general, a product's manufacturing procedure ends with a surface finishing process which in most cases is a grinding process. The reason for this process is its robustness in combination with the possibility to achieve a high dimensional accuracy as well as the desired surface quality. Grinding is a highly energy- and tool material-consuming process. This is why industry has a big demand for efficient grinding tools, that is to say tools having a high material removal rate in combination with a long service life. The high energy consumption is due to the extremely negative rake angles, the random geometry of the cutting edge and the low cutting chip thickness of $0.01-100 \mu \mathrm{m}$ [1-3] resulting in high chip compression, in hindered chip removal and in high amount of friction.

A monolayer grinding tool satisfies the industrial prerequisites which are to withstand lots of grinding cycles without failure and severe wear. Only super-abrasives such as diamond and cubic boron nitride are suitable [4-10]. The preferred bonds are metallic which are achieved by brazing or electroplating due to their high-retention capabilities $[6-8,10-14]$. In case of electroplating, the retention is purely mechanical, i.e. interlocking; whereas during brazing, a strong chemical bond is created $[15,16]$.

In contrast to the first generation monolayer grinding tools exhibiting a random distribution of the grits [6-8], the arrangement of the grains has been optimised with regard to the desired application in the recent time $[4,9$, $10,14,17-19]$. Monolayer grinding tools with a predefined grain pattern are named "engineered grinding tools" (EGT). Guidelines for its optimization can be drawn by applying different simulation techniques [11, 17, 19-21]. The optimised grit arrangement $[4,5,17,19,22,23]$ allows a higher grinding speed due to lower measured grinding forces. EGTs are principally used for the fast and effective material removal. The lower grain density is responsible for the 
rougher surface; therefore, a subsequent grinding operation for achieving the required surface quality today is still necessary $[21,24]$. The major drawback of the EGT is their sensitivity to layering failures. If an abrasive grain cannot withstand the load, it will fail and the subsequent grain is then subjected to much higher loads. The grain will either immediately fracture or it will wear out quickly until it breaks. This process will proceed until all grains in a circumference are irreparably worn and damaged [21].

An engineered grinding tool with its predefined pattern can be seen as a network of single abrasive grains. Each of the single abrasive grains has to work for itself and to withstand the grinding forces. The forces strongly depend on the scratch characteristics, e.g. area of work-hardened material and burrs made by the previous grain. Therefore, as a simple model, one can consider the whole engineered grinding tool as a collection of individual abrasive grains contributing to the tool's overall performance. Single grain scratching tests are a powerful tool to investigate the properties of the grain material interaction, e.g. failure mechanisms and cutting behaviour. The results can be used to synthesise the properties of the grinding wheel as a whole. Electroplated single diamond grains mostly fractured $(60 \%)$ at the non-engaged rear edge, which means that the rear part of the diamond grain splits off [25]. Two possible failure mechanisms of brazed diamond grains exist, i.e. diamond fracture and pullout. A fast means to provoke diamond fracture is to overload the grain due to a strong impact during engaging into the workpiece material, which in case of grinding should be at all times avoided [26]. The consequence of an interface failure is grain loss, a so-called grain pullout. During the brazing of diamond, an interlayer has to be developed in order to provide wetting and bonding. A mechanically weak interlayer retains poorly the grain, whereas excessive brazing temperatures and dwell times cause thick interlayers which are prone to internal defects [27-29]. A grain pullout also occurs as a failure mechanism when the filler alloy is abraded and corroded. The effects are a loosening of the grain, leading to a dislodging from the bonding and finally to grain pullout [30].

In literature, the fracture of solids is commonly described by three different fracture types, namely elastic, elastoplastic or plastic fracture $[31,32]$. In case of elastic fracture, observed for brittle materials (e.g. ceramics and diamond), the solid fractures before reaching its yield strength. Existing crystal defects or microcracks can act as a stress concentrator and exaggerate the stress in front of the crack tip. The material behaves in an elastic way and for this reason, no deformation takes place. The fracture strength can be estimated with the Griffith equation. Its counterpart is the plastic fracture, observed for tough materials (e.g. metals and alloys), where fracture occurs at stresses much higher than the yield strength. This corresponds to an extensive plastic deformation at the crack tip. The crack is only a weak stress concentrator. If only small yielding occurs, then it is denoted as elastoplastic fracture.

The cutting characteristics of diamond grains depend on many parameters, e.g. rake angle, shape of the grain, cutting speed and depth of cut. Micro-cutting tests using pyramidal diamonds revealed a significant influence of the apex angle (=double-negative rake angle) on the normal and on the tangential forces. The lower the apex angle or rake angle, respectively, the lower are the measured forces [33, 34]. In [35], the same behaviour was found as well as that the effect of the rake angle is larger for the normal force than for the tangential force. The influence of the diamond grain shape is insignificant for the tangential force $F_{t}$ in comparison with the normal force $F_{n}$. Furthermore, the lateral bulging, the chip formation and the material removal strongly depend on the orientation of the grain towards the cutting direction [36]. At low cutting speeds, i.e. $v_{c}=0.3-5 \mathrm{~m} / \mathrm{s}$, in combination with low chip thicknesses the chip formation will be governed by the less efficient microploughing mechanism. The desired efficient microcutting mechanism is obtained at high cutting speeds and high chip thicknesses [37].

The scratching of cemented paste or oil well cement with a steel cutter blade $[38,39]$ results in a power law between tangential force and scratch area. Replacing the cement by paraffin leads to changes in this relationship [40]. In this case, for small scratch areas, a linear relationship is found; whereas at larger scratch areas, the increase in force is smaller than the increase in scratch area. Thus, the linear relationship changes into a power law. In the linear regime, the stress is limited to the strength of the workpiece material, whereas in the power law regime fracture dominates the scratching process.

In the literature, the focus is on the wear of diamond grains and not on their failure, since wear already impairs the grinding tool performance, which is bad for the manufacturing accuracy. However, the understanding of the grain failure is also necessary, due to the fact that the use of a wrong filler alloy can lead to premature and unexpected grain failure. Furthermore, excessively harsh grinding conditions could be prevented by defining critical failure forces or depths of cut.

In the context of grinding, knowledge about the failure mechanisms as well as the cutting characteristics is essential. The recording of failure forces as a function of critical depths of cut, feed rate or grinding wheel speed gains new information for a more tool service lifeoriented construction and a better choice of operation conditions. In the present work, the failure mechanisms were determined using different grain sizes and brazing filler alloys. 


\section{Experimental}

\subsection{Materials and brazing process}

The applied test specimens were composed of three parts: a steel substrate, an active filler alloy and a diamond grain. The substrate material was X2CrNiMo 18-14-3 (AISI 316L). This material is used for tool bodies in the grinding industry and is suitable for the applied brazing temperatures as it has no phase transformation. The sample exhibited a diameter of $6.0 \mathrm{~mm}$ and a height of $25.0 \mathrm{~mm}$ as well as a thread of $12.0 \mathrm{~mm}$ length for fixing the bolt (see Fig. 1).

Two active filler alloys were considered; an Ag-Cu-based one and a $\mathrm{Cu}-\mathrm{Sn}$-based one, both with titanium as active element. The Ag-Cu-based active filler (63.25 $\mathrm{wt} \% \mathrm{Ag}-$ $35 \mathrm{wt} \% \mathrm{Cu}-1.75 \mathrm{wt}^{\mathrm{o}} \% \mathrm{Ti}$, Cusil- $-\mathrm{ABA}^{\mathrm{TM}}$ ) is produced by Wesgo Metals (Hayward, CA, USA). It is applied as a powder of -325 mesh size (maximum particle size, $\approx 35 \mu \mathrm{m}$ ). The solidus and liquidus temperatures are 780 and $815^{\circ} \mathrm{C}$ according to [41]. The Cu-Sn-based filler alloy named Diabraze ${ }^{\mathrm{TM}}$ (73.9 wt \% Cu-14.4 wt\% Sn-10.2 wt\% Ti-1.5 wt\% Zr, Sulzer Metco (Hattersheim, Germany)) had an average powder particle size of $12 \mu \mathrm{m}$. Its solidus and liquidus temperatures are 868 and $925{ }^{\circ} \mathrm{C}$, respectively [42]. The filler alloys were mixed with a binder to obtain a paste, which was directly applied to the sample and dried at $150{ }^{\circ} \mathrm{C}$ afterwards. The brazing process in a Torvac high vacuum furnace $\left(p=10^{-5}-10^{-6} \mathrm{mbar}\right.$, Cambridge Vacuum Engineering LTD, Cambridge, UK) using Cusil-ABA as filler alloy was carried out at $850{ }^{\circ} \mathrm{C}$ for $10 \mathrm{~min}$ and using Diabraze at $930{ }^{\circ} \mathrm{C}$ for $10 \mathrm{~min}$.

Diamond grains of various sizes ((D251), D356, D501 and D851) were applied for the specimens. The actual grain sizes in micrometre are displayed in Table 1. These grains were MBS 970 produced by Diamond Innovations

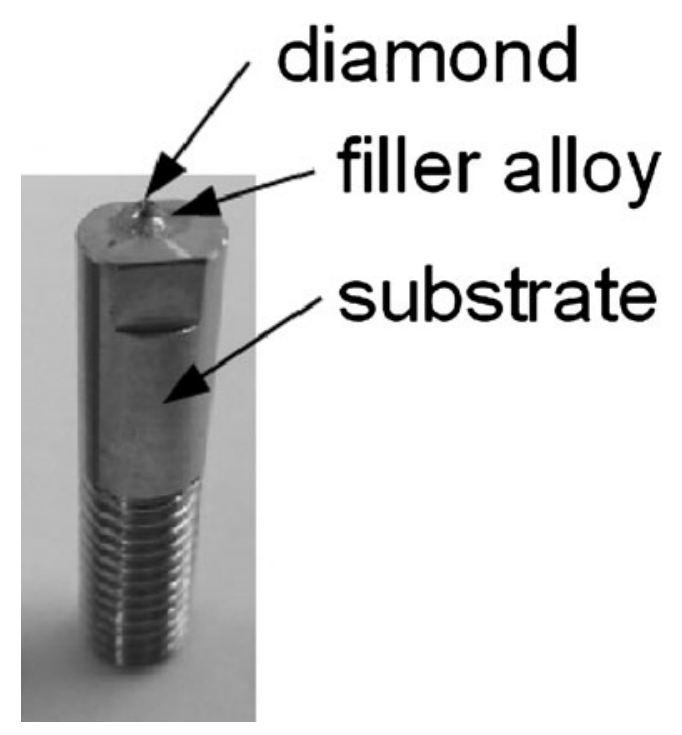

Fig. 1 Overview of the applied sample geometry
Table 1 Diamond grain sizes

\begin{tabular}{ll}
\hline Designation & Grain size $(\mu \mathrm{m})$ \\
\hline D251 & $212-250$ \\
D356 & $300-355$ \\
D501 & $425-500$ \\
D851 & $710-850$ \\
\hline
\end{tabular}

(Worthington, OH, USA), which have a low aspect ratio and are narrowly distributed. Different sizes were applied in order to investigate if there is any dependency in failure mechanisms, critical forces and critical depth of cut on the grain size. The measured force and depth of cut at the site of grain failure are denoted as critical force and critical depth of cut. Two different grain orientations were distinguished, denoted as octahedral and cubic orientation, which can be seen in a brazed state in Fig. 2a and b, assuming an influence on the occurring failure mechanisms. The diamond grains were chosen for the tests because these polyhedral grains are the standard grains in industrial grinding tools. The mechanical properties of the applied materials are listed in Table 2 [41, 43-49].

\subsection{Experimental methods}

Prior to the single grain tests, the diamond was oriented under a $3 \mathrm{D}$ light microscope. The engagement orientation was adjusted in such a way that the longest undamaged diamond edge engaged into the workpiece material (see Fig. $2 \mathrm{a}$ and $\mathrm{b}$ ). This signifies that the engagement edge was perpendicular to the cutting direction. Due to the morphology of the diamond grain, the rake angle $\gamma$ and the clearance angle $\alpha$ are dependent on each other, as depicted in Fig. 3. Therefore, only one of the two mentioned angles had to be determined and the other is consequently given from the crystallographic relationship, i.e. in case of (100)-(111) orientation: $\gamma=-\left(35.3^{\circ}+\alpha\right)$ and in case of (111) $-(111)$ orientation: $\gamma=-\left(19.5^{\circ}+\alpha\right)$. If the octahedral orientation was used, the rake face is either a (100) or a (111) plane. The mechanical properties, like hardness, Young's modulus or fracture strength are different for the applied two crystallographic directions. If the cubic orientation was applied, the (111) plane is always the rake face. The experiments were run with both the octahedral and cubic orientation in order to investigate eventually different failure and cutting behaviours.

The experiments were performed on a conventional threeaxis computer numerical control milling machine Mikron VC 1000 (Mikron Holding AG, Biel, Switzerland). Pictures of the test setup are shown in Fig. 4a and a sketch of the procedure is depicted in Fig. 4b. The spindle moved in a linear direction with a constant cutting velocity $v_{c}$ across the workpiece $\left(v_{c}=\right.$ $0.18 \mathrm{~m} / \mathrm{s}$ ). The dynamometer and the mounted workpiece were adjusted in order that the axial force component almost completely vanished, i.e. cutting force $F_{c}$ is equal to tangential 
Fig. 2 Micrographs of the a octahedral and $\mathbf{b}$ cubic orientation of a brazed diamond with the indication of the engagement edges
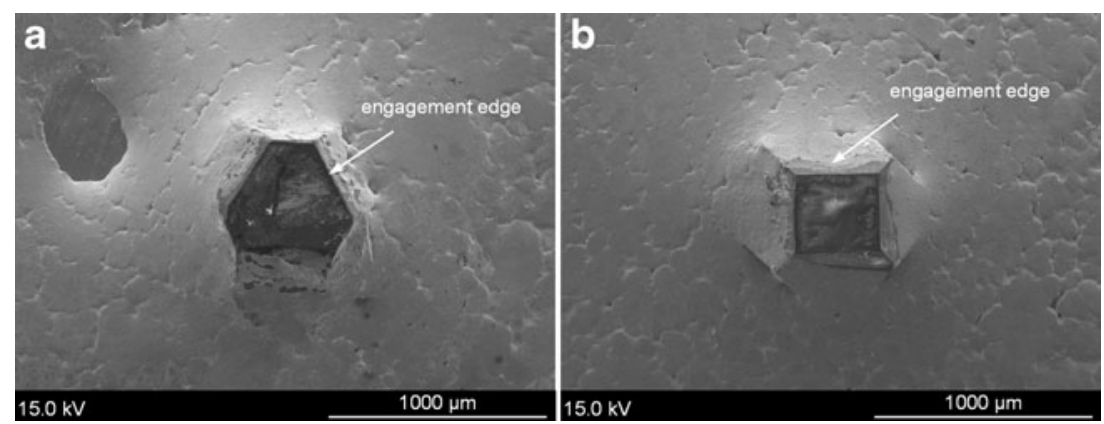

force $F_{t}$. The workpiece had the dimensions $80.0 \times 40.0 \times$ $8.0 \mathrm{~mm}$ and was made of case-hardened $15 \mathrm{NiCr} 13$. The carbon content at the surface was approximately $0.7 \mathrm{wt} \%$. Its surface was polished and exhibited a hardness of HRC $60 \pm 1$. It was mounted on a calibrated multi-component dynamometer Kistler MiniDyn 9256C1 (Kistler Instrumente AG, Winterthur, Switzerland). A sampling rate of $6 \mathrm{kHz}$ was used and the three signals of the force components were low-pass filtered with a frequency of $400 \mathrm{~Hz}$. Since the workpiece was not fully even, the scratch area slightly increased within one scratch, corresponding to an increase in the detected forces. The scratch area was manually increased in steps of 5-10 $\mu \mathrm{m}$ for the next scratch, if failure had not occurred; this fact is displayed in Fig. 4b on the right side. Afterwards, the failure mechanisms of the brazed diamond grains were investigated.

A 3D picture of the scratch at failure site was taken using a 3D light microscope. The used test setup is displayed in Fig. 5a. In Fig. 5b, the procedure is schematically shown; in a distance of 100-200 $\mu \mathrm{m}$ in front of the failure site the scratch volume $V_{\text {scratch }}$ was determined from the 3D picture. The width $w$ of the volume measurement area is known and the division results in $A_{\text {scratch }}$. The errors in $A_{\text {scratch }}$ are $4.3 \%$ (D356), $4.7 \%$ (D501) and 1.8\% (D851).

\section{Results}

\subsection{Failure mechanisms}

The micrographs of failed D851 diamonds brazed with the $\mathrm{Au}-\mathrm{Cu}$-based filler alloy are shown in Fig. 6a-d. The failure mechanisms are "grain pullout" (Fig. 6a) and "grain fracture" (Fig. 6b-d). In case of "grain fracture", the failure mechanism is distinguished into coarse (Fig. 6b) and fine splintering (Fig. 6c and d). The characteristic of coarse splintering is the existence of a large piece of the original diamond, whereas in case of fine splintering the whole diamond is destroyed and either the filler alloy "crater" is filled with diamond debris (Fig. 6c) or it is almost empty (Fig. 6d). The failure mechanism in Fig. 6d is assigned to be "grain fracture", since no plastic deformation of the filler alloy cone occurred (compared to Fig. 6a) and diamond splinters are detected at the bottom of the filler alloy crater. The failure mechanisms do not depend on the grain size and on the filler alloy composition, but the percentage of the occurred failure mechanism and the forces at failure depend on it, see Figs. $7 \mathrm{a}-\mathrm{c}$ and $8 \mathrm{a}-\mathrm{c}$, so the failure is stochastic.

Since the results for a certain grain size are very similar for both the octahedral and the cubic grain orientation, i.e. the results are within the error range in combination with the requirement for an adequate number of samples for obtaining a good statistics; the specimens are evaluated all together.

The results in Fig. $7 \mathrm{a}-\mathrm{c}$ were obtained for the $\mathrm{Ag}-\mathrm{Cu}-$ brazed diamonds. The dependence of the failure mechanism on the grain size is given in each of the diagrams. There is a tendency for "grain pullout" for small grains and a slightly higher probability of "grain fracture" for big grains. The percentages are: $66.7 \%$ pullout and $33.3 \%$ fracture for D356, and $44.8 \%$ pullout and $55.2 \%$ fracture for D851. In case of D501 the ratio is 50.0-50.0\%. The measured forces at failure are given in Fig. 7a, too. The obtained normal forces are larger than the tangential ones. For D356 and D501, the critical forces for pullout and fracture are very similar, whereas in case of D851 the pullout forces
Table 2 Mechanical properties of the materials [41, 43-49]

${ }^{\mathrm{a} C}$ Compressive fracture strength on (111) surface

\begin{tabular}{lllll}
\hline Material & $\begin{array}{l}\text { Young's modulus } \\
(\mathrm{GPa})\end{array}$ & $\begin{array}{l}\text { Yield strength } \\
(\mathrm{MPa})\end{array}$ & $\begin{array}{l}\text { Tensile strength } \\
(\mathrm{MPa})\end{array}$ & $\mathrm{K}_{\mathrm{Ic}}\left(\mathrm{MPa} \cdot \mathrm{m}^{1 / 2}\right)$ \\
\hline X2CrNiMo 18-14-3 & 200 & 200 & $500-700$ & 50 \\
Cusil-ABA & 83 & 271 & 346 & - \\
Cu-20Sn-10Ti & - & 550 & 820 & - \\
Diamond & 1,050 & - & 3,750 & $4-5$ \\
& & & $7,500-12,500^{\mathrm{a}}$ & \\
\hline
\end{tabular}


Fig. 3 Schematic of the dependency of the clearance angle $\alpha$ and the rake angle $\gamma$
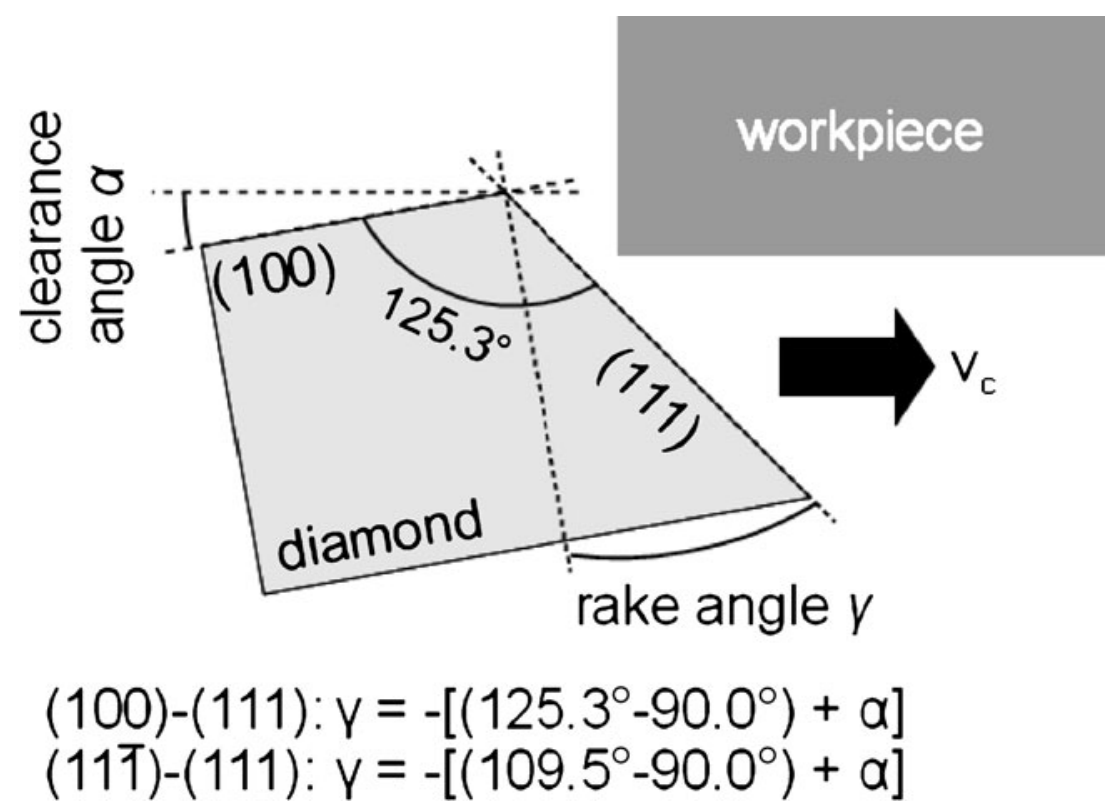

are significantly higher than those for fracture. The critical forces increase with increasing grain size from roughly $50 \mathrm{~N}$ (D251) to $300 \mathrm{~N}$ (D851). The two grain sizes D356 and D501 exhibit rather similar forces and scratch areas. This fact is depicted in Fig. 7a and b. Like critical forces, the critical scratch areas also increase with increasing grain size. The scratch areas for pulled-out grains are always larger than the scratch areas for fractured ones. It is obvious that the forces and the scratch areas increase with larger grits at the same interaction depth due to the higher removed material volume. In order to compare the grain sizes to each other, the critical forces are divided by the critical scratch areas as shown in Fig. 7c. This diagram shows that the values of "grain fracture" are always higher (about 5,000 $20,000 \mathrm{~N} / \mathrm{mm}^{2}$ ) than those for "grain pullout". Comparing the $F_{F, C} / A_{\text {scratch }}$ values for pulled out grains to the different grain sizes, it is recognised that the values are very similar possessing a slight trend to decrease for larger grains from $19,800 \mathrm{~N} / \mathrm{mm}^{2}$ (D356) to $17,100 \mathrm{~N} / \mathrm{mm}^{2}$ (D851). This behaviour is also found for grain fracture, i.e. from $25,900 \mathrm{~N} / \mathrm{mm}^{2}$ (D356) to $22,200 \mathrm{~N} / \mathrm{mm}^{2}$ (D851). The knowledge of the interface area $A_{\mathrm{br}}$ between filler alloy and diamond allows the calculation of a kind of bond strength $\tau=F_{F, c} / A_{\mathrm{br}}$. Considering only "grain pullout", the bond strength is almost independent of the grain size with $\tau=(162 \pm 52) \mathrm{MPa}$.

In Fig. 8a-c, the obtained results for the $\mathrm{Cu}-\mathrm{Sn}$-brazed diamonds are displayed. Here, the transition in the failure mechanism is more apparent (see Fig. 8a). The percentage of "grain pullout" decreases in the order D356-D501-D851 from $91.7 \%$ via 41.7 to $33.3 \%$; consequently, the percentage of "grain fracture" increases from $8.3 \%$ via 58.3 to $66.7 \%$. It also applies here that the normal forces are larger than the tangential (cutting) forces (see Fig. 8a). In case of D356 and D501, the critical pullout forces are larger than the critical fracture forces. The critical cutting force of the two D851 failure mechanisms is equal with $F_{F c} \approx 260 \mathrm{~N}$, whereas the normal forces strongly vary between $F_{F, n} \approx 265 \mathrm{~N}$ (pullout) and $F_{F, n} \approx 335 \mathrm{~N}$ (fracture). The trend to higher critical forces and higher critical scratch areas with larger sizes is evident from the graphs shown in Fig. 8a and b. The larger the grain size, the larger the critical scratch areas. Furthermore, the scratch area for "grain pullout" is larger than those for grain
Fig. 4 Pictures a and sketch b of the experimental test setup

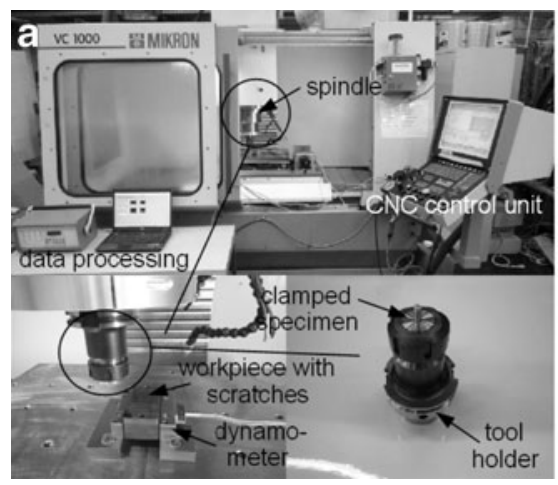

b

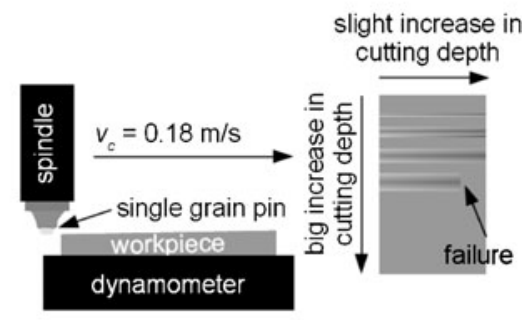


Fig. 5 Evaluation of $A_{\text {scratch }}$ : a test setup and $\mathbf{b}$ procedure
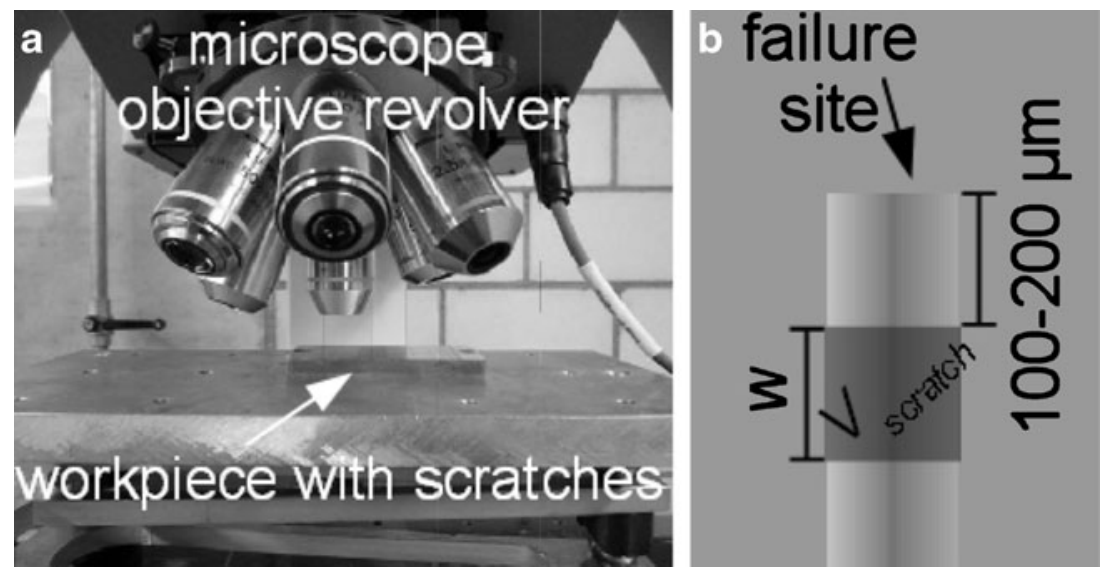

fracture for all tested grain sizes. Both the critical forces and the scratch areas rise with increasing grain size due to the higher quantity of removed material. The ratios of $F_{F c, n} /$ $A_{\text {scratch }}$ are shown in Fig. 8c. In case of D356 and D851, the ratio has higher values for the failure mechanism "grain fracture", whereas it is vice versa in case of D501 diamonds. The $F_{F, d} / A_{\text {scratch }}$ ratio as a function of the grain size has a monotonic decrease for "grain fracture" form $38,500 \mathrm{~N} / \mathrm{mm}^{2}$ (D356) to $18,400 \mathrm{~N} / \mathrm{mm}^{2}$ (D851) and a tendency to decrease for the "grain pullout". The bond strength of the $\mathrm{Cu}$-Sn-brazed diamond grains is $\tau=(237 \pm 58) \mathrm{MPa}$.

A comparison of the failure mechanisms for diamonds brazed with $\mathrm{Ag}-\mathrm{Cu}$-based and $\mathrm{Cu}-\mathrm{Sn}$-based filler alloy leads to the following results: The alteration of the failure mechanisms from "grain pullout" (small grit) to "grain fracture" (large grit) is equal, whereas the actual percentage differs. The critical cutting forces for the $\mathrm{Cu}-\mathrm{Sn}$ filler alloy are higher for D851 $\left(\Delta F_{F, c} \approx 100 \mathrm{~N}\right)$ and for D501 $\left(\Delta F_{F, c} \approx\right.$
$40 \mathrm{~N}$ ). The cutting force for the smallest grain size is equal with $\approx 100 \mathrm{~N}$. The bond strength for the $\mathrm{Cu}$-Sn-brazed diamonds $(\tau \approx 240 \mathrm{MPa})$ is $\approx 33 \%$ higher than for the $\mathrm{Ag}$ - $\mathrm{Cu}$ brazed ones $(\tau \approx 160 \mathrm{MPa})$. The $F_{F, c} / A_{\text {scratch }}$ ratio for the Ag$\mathrm{Cu}$-based filler alloy exhibit nearly constant values, dependent on the failure mechanism, but independent of the grain size. In case of the $\mathrm{Cu}$-Sn-based filler alloy, these values are strongly different.

\subsection{Cutting characteristics}

Due to the large number of specimens, a lot of different scratch areas $A_{\text {scratch }}$ were achieved for two different rake angles, explicitly $-19.5^{\circ}$ and $-35.3^{\circ}$, both with a clearance angle of $0^{\circ}$ (cf. Fig. 3). In Fig. 9a and b, the cutting and normal force for all tested samples are plotted against the scratch area. Both forces rise with increasing scratch area. The investigation of the influence of the two different rake
Fig. 6 SEM pictures of the different occurred failure mechanisms: a grain pullout, $\mathbf{b}$ coarse splintering of the grain, and $\mathbf{c}$ and $\mathbf{d}$ fine grain splintering
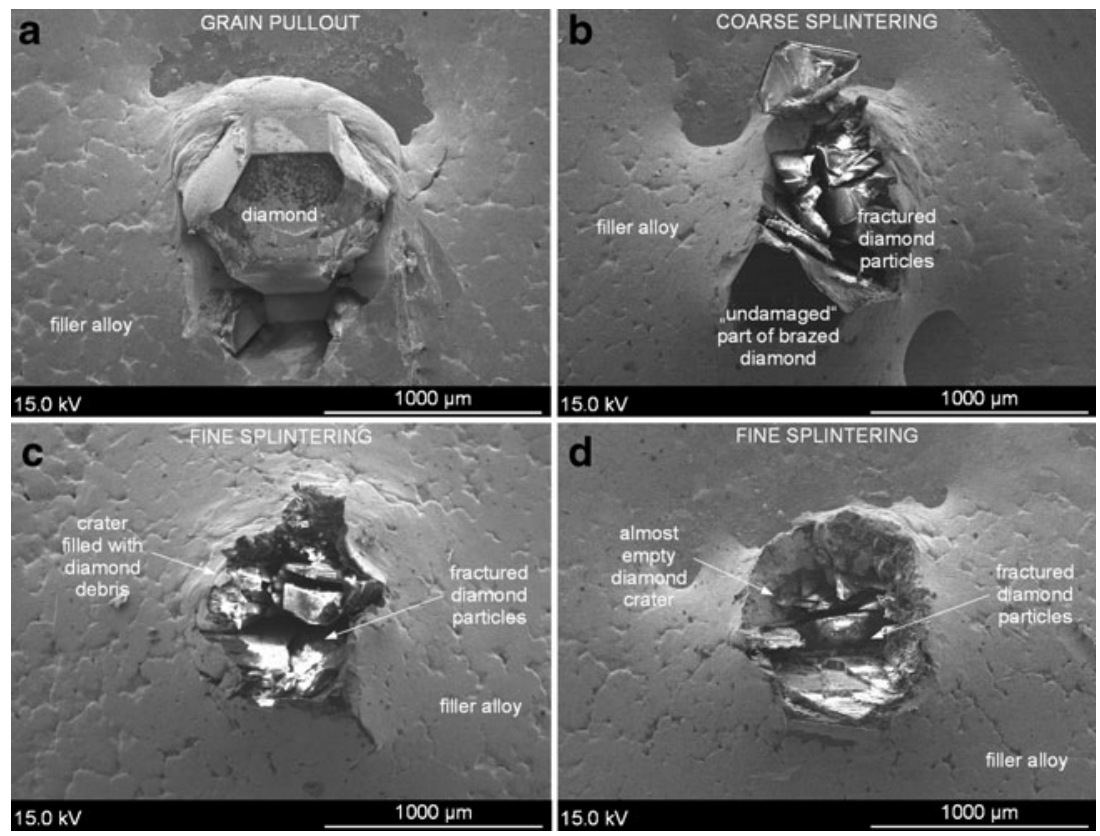
Fig. 7 Failure characteristics of Ag-Cu-brazed diamond grains in dependence of the grain size ( $[X]=$ number of samples): a percentages and $F_{c}, F_{n}$ failure forces, $\mathbf{b}$ scratch area $A_{\text {scratch }}$ at failure and $\mathbf{c}$ calculation of $F_{c} / A_{\text {scratch }}$ and $F_{n} / A_{\text {scratch }}$ in order to compare the different grain sizes

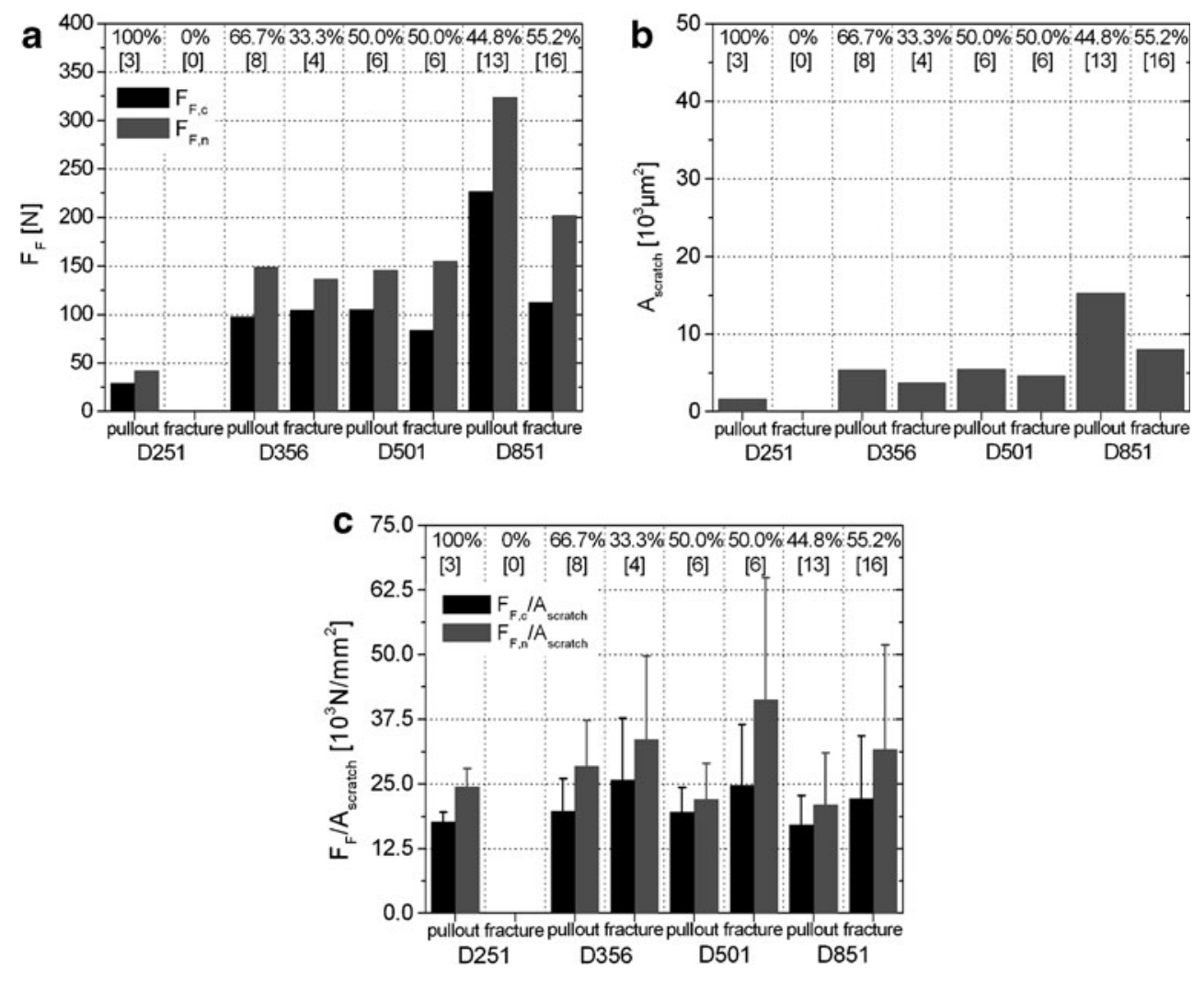

angles is displayed in Fig. 10a and b. In order to have a sufficient number of data points, all diamond grains exhibiting rake angles of $(-19.5 \pm 2)^{\circ}$ and $(-35.3 \pm 2)^{\circ}$ were taken for the evaluation. In cutting processes, the relationship between cutting force and scratch depth is described by the Kienzle equation. In this work, since the scratch area
Fig. 8 Failure characteristics of $\mathrm{Cu}$-Sn-brazed diamond grains in dependence of the grain size ([X]=number of samples): a percentages and $F_{c}, F_{n}$ failure forces, $\mathbf{b}$ scratch area $A_{\text {scratch }}$ at failure and $\mathbf{c}$ calculation of $F_{c} / A_{\text {scratch }}$ and $F_{n} / A_{\text {scratch }}$ in order to compare the different grain sizes
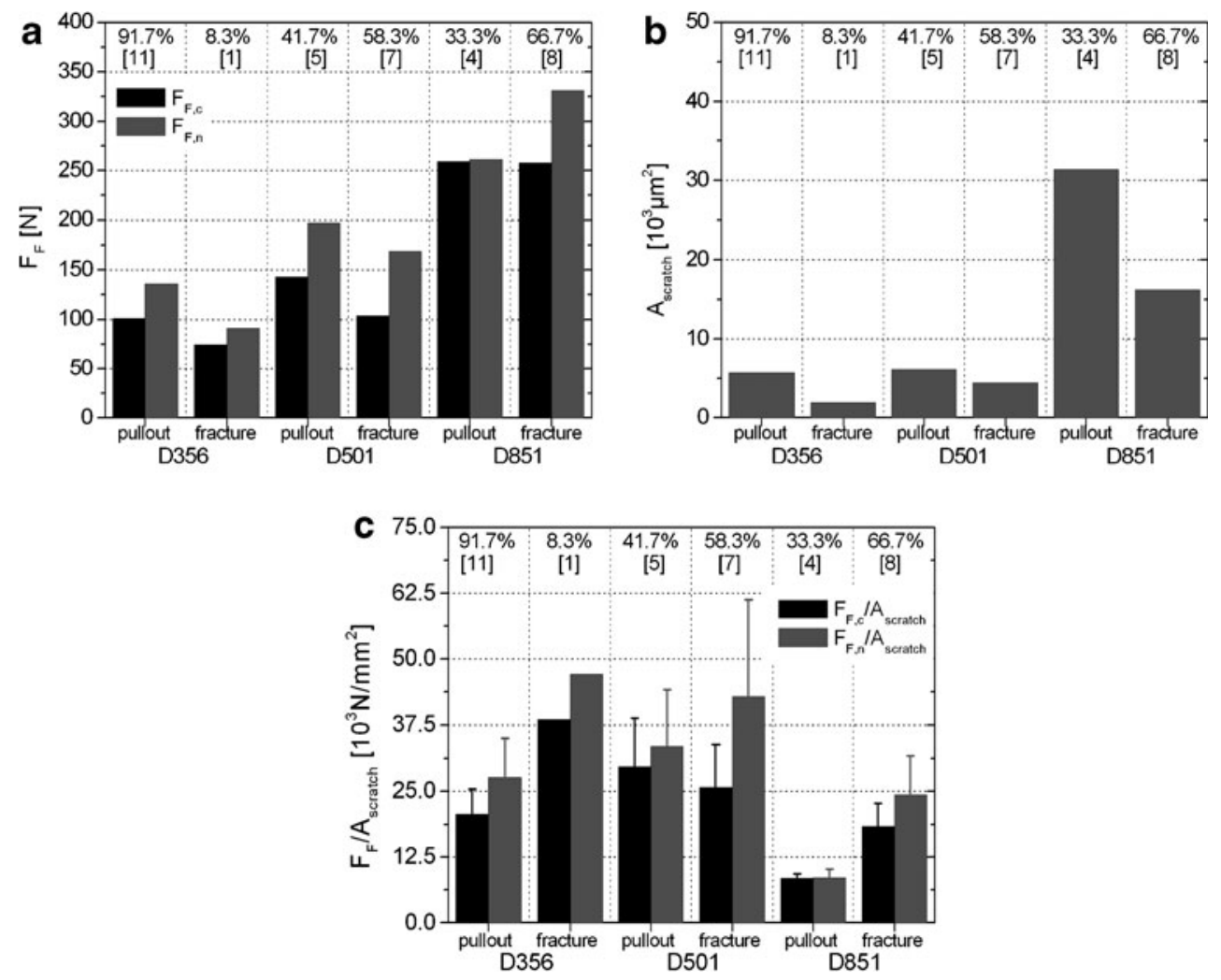
Fig. 9 Plot of $\mathbf{a} F_{c}$ and $\mathbf{b} F_{n}$ vs. $A_{\text {scratch }}$
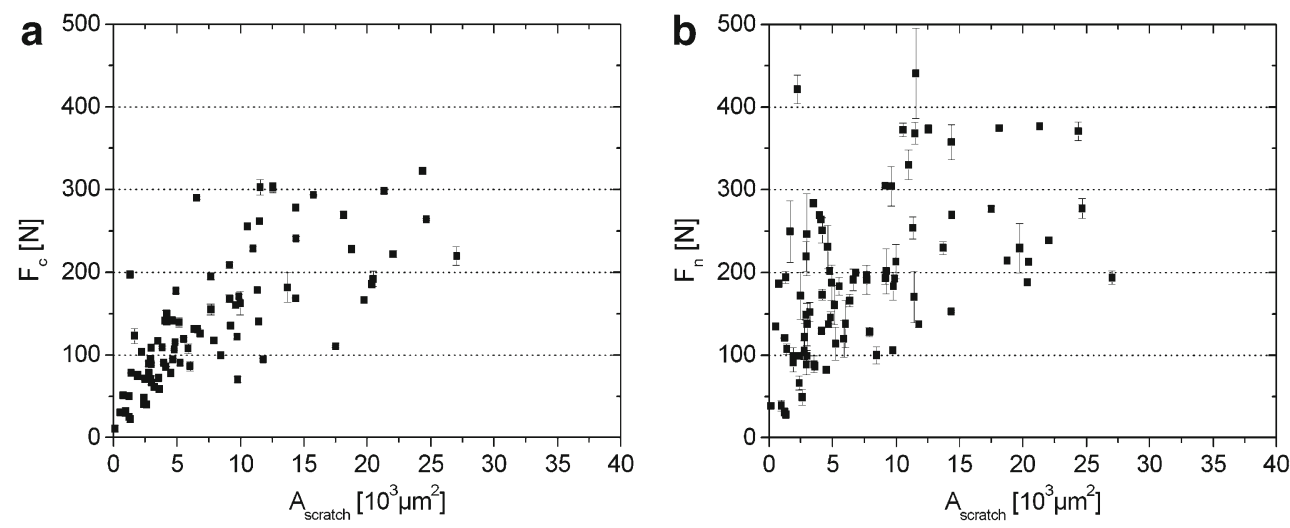

can be more accurately evaluated, the data points are fitted by a Kienzle-like equation:

$F_{c, n}=k \cdot\left(A_{\text {scratch }}\right)^{n_{c, n}}$

The presented lines are the best fit of the whole ensemble of data points. The data points in brackets were not considered in fitting. The powers $n_{c}$ of the cutting force as a function of the rake angle are $n_{c,-19.5^{\circ}}=(0.50 \pm 0.12)$ and $n_{c,-35.3^{\circ}}=(0.67 \pm$ $0.09)$. In case of normal force, the obtained powers $n_{n}$ are: $n_{n,-19.5^{\circ}}=(0.19 \pm 0.11)$ and $n_{n,-35.3^{\circ}}=(0.57 \pm 0.12)$. The values indicate that the cutting force increases faster than the normal force with increasing scratch area. It can also be seen that the more negative rake angle has the higher cutting and normal forces for all scratch areas. The intersection in case of normal force is most probably due to the lack of data points in the small scratch area region. It is evident from the results that the geometry and particularly the rake angle strongly control the cutting forces.

\section{Discussion}

\subsection{Failure mechanisms}

The observed failure mechanisms are "grain pullout" and "grain fracture". Erosion of the filler alloy bond did not happen because this requires flushing of debris, chips, broken diamond particles as well as high velocities, which is not given by the used test setup with single grains. A common trend in failure mechanism is observed. Small grains are more frequently pulled out, whereas the larger ones mainly break. Luo et al. [50] conducted wear experiments with Co-bronze bonded diamond grains (D301/ D356); they demonstrated that the small grains exhibit a higher proportion of "grain pullout" compared to "grain fracture".

A simple mechanical model for a brazed diamond is used to support the transition of the failure mechanism. First, the influences on the occurrence of the different failure mechanisms are identified. The retention force of the filler alloy is connected to the interfacial strength of diamond-filler alloy. Furthermore, the strength of the filler alloy is decisive for the supporting effect of the surrounding filler alloy cone. Due to the applied test setup, a bending torque is exerted on the diamond grain, provoking a bending stress. Especially for brittle materials, the probability of any imperfection in the diamond like impurity atoms, inclusions or pre-cracks is important, since it determines the failure strength. The failure strength of diamonds shows a strong decrease with increasing size [43, 51-53] as shown in Table 3 for synthetic diamonds [51]. The failure strength was determined by continuously loading a diamond grain, which is positioned in-between two anvils, until fracture. The applied model is
Fig. 10 Dependence of a the cutting force $F_{c}$ and $\mathbf{b}$ the normal force $F_{n}$ on the scratch area $A_{\text {scratch }}$ with the corresponding fitting equations
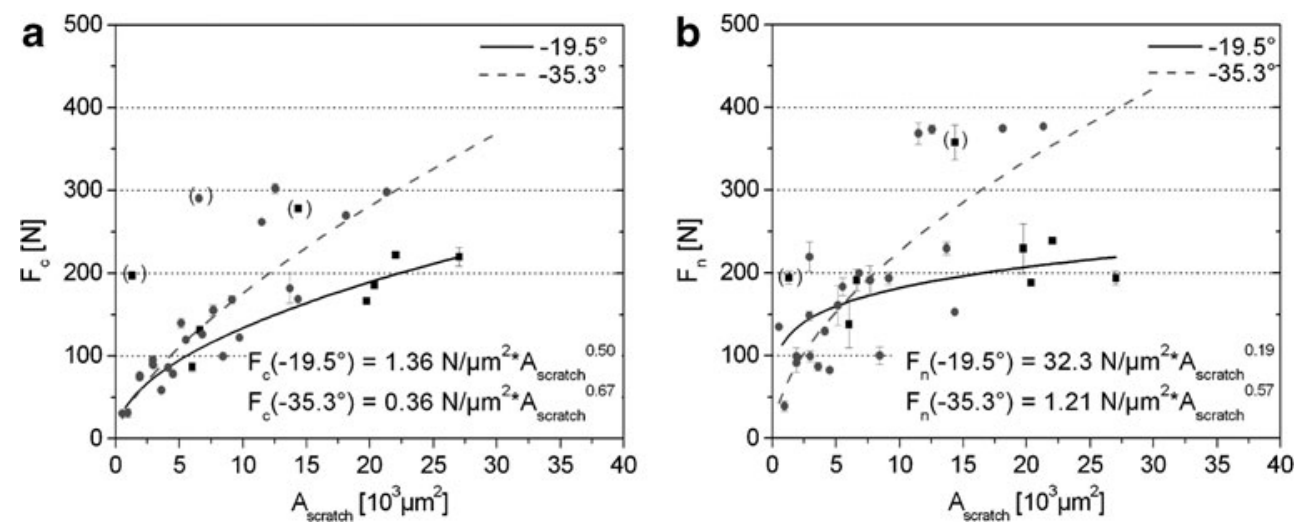
Table 3 Failure strength of different synthetic diamond grain sizes [51]

\begin{tabular}{ll}
\hline Grain size $(\mu \mathrm{m})$ & Failure strength $(\mathrm{GPa})$ \\
\hline $300-400$ & $11.1 \pm 1.1$ \\
$500-600$ & $6.5 \pm 1.6$ \\
$700-800$ & $4.5 \pm 1.7$ \\
$800-1,000$ & $3.5 \pm 1.0$ \\
\hline
\end{tabular}

sketched in Fig. 11. For simplicity, a regular hexagon with the dimension $a$ is assumed for the diamond geometry. The value $a$, as indicated in Fig. 11, is half of the maximum particle size. The averaged forces $F_{F, \mathrm{~cm}}$ and $F_{F, \text { nm }}$ were taken from the measurement and calculated independently of failure mechanisms and filler alloy for one grain size. $A_{\text {facet }}$ is the mean area for one single diamond facet. It is obtained from numerous 3D pictures of diamond facets of diamond grains having different grain sizes. The pictures were taken with a 3D light microscope and evaluated. A summary of the aforementioned values is given in Table 4 . The bending stress $\sigma_{b}$ and contact stress, i.e. normal stress $\sigma_{n}$ and shear stress $\tau$, were evaluated. The maximum bending stress shown as hatched circle in Fig. 11, which exhibits the highest bending torque, is calculated according to

$\sigma_{b}=M_{b} / W_{b}$

where $M_{b}$ is the bending torque and $W_{b}$ is the section modulus. The section modulus of a hexagonal crosssection is used since it resembles most the grain's geometry. The contact stresses acting on $A_{1}, A_{2}$, and $A_{3}$ are evaluated by:

$\sigma^{*}=F_{F, \mathrm{~nm}} /\left(7 \cdot A_{\text {facet }}\right)$

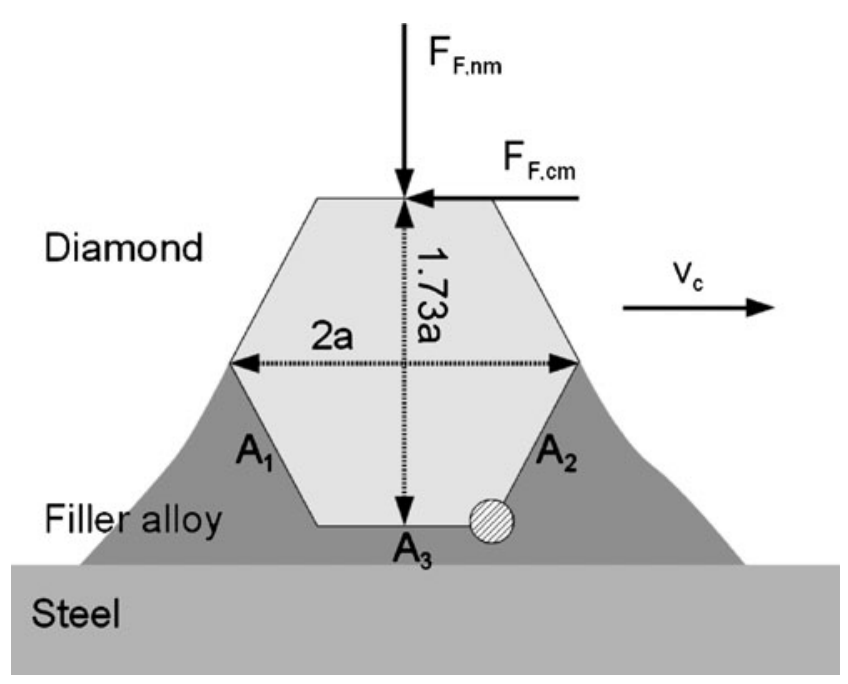

Fig. 11 Sketch of the used model
Table 4 Input values for the model

\begin{tabular}{lllll}
\hline Grain size & $a(\mu \mathrm{m})$ & $A_{\text {facet }}\left(\mathrm{mm}^{2}\right)$ & $F_{F, \mathrm{~cm}}(\mathrm{~N})$ & $F_{F, \mathrm{~nm}}(\mathrm{~N})$ \\
\hline D356 & 178 & 0.033 & 94.7 & 128.4 \\
D501 & 250 & 0.070 & 109.1 & 166.8 \\
D851 & 425 & 0.220 & 214.1 & 279.1 \\
\hline
\end{tabular}

$\tau^{*}=F_{F, \mathrm{~cm}} /\left(7 \cdot A_{\text {facet }}\right)$

The denominator $\left(7 \cdot A_{\text {facet }}\right)$ is due to the fact that a diamond embedding of $50 \%$ corresponds to seven embedded facets. These two stresses are decomposed into the normal stress $\sigma_{n}$ acting perpendicular to the diamond-filler alloy interface and into the shear stress $\tau$ acting in the diamond-filler alloy interface. The results obtained with this model are shown in Tables 5 and 6 and evaluated as follows. According to the model, for a grain pullout, the shear stresses at the interfaces $A_{2}\left(A_{3}\right)$ as well as a large (negative) normal stress at the interface $A_{1}$ are decisive. Both stresses are significantly higher for smaller grain sizes. The shear stresses in the interface $A_{2}$ and the normal stresses on the interface $A_{1}$ are the biggest ones for the smallest grains. The high shear stresses favour crack initiation and interfacial crack growth. The high normal stresses on the rear part of the filler alloy cone $\left(A_{1}\right)$ lead to plastic deformation. The result is a loss in the supporting effect and a grain loosening. A comparison between the normal stress and the filler alloy's yield strength show that for the smallest grains the yield strength is exceeded. The failure strength (see Table 3) is in the same range like the bending stress and therefore sometimes prevents the grain fracture. The high shear and normal forces as well as the high failure strength of the diamond grains favour grain pullout for small diamond grains. The criterion for grain fracture is the exceeding of the failure strength due to the presence of bending stresses in the diamond grain. The bending torque is the largest one for the biggest grain, but the bending stress is the smallest one due to the big section modulus. A comparison between bending stress and failure strength of the different grain sizes results in the fact that the failure strength decreases more rapidly than the bending stress with increasing grain

Table 5 Bending moment $\left(M_{b}\right)$ and bending stress $\left(\sigma_{b}\right)$

\begin{tabular}{lll}
\hline Grain size & $\begin{array}{l}\text { Bending moment }\left(M_{b}\right) \\
(\mathrm{N} \cdot \mathrm{mm})\end{array}$ & $\begin{array}{l}\text { Bending stress }\left(\sigma_{b}\right) \\
(\mathrm{GPa})\end{array}$ \\
\hline D356 & 40.6 & 11.5 \\
D501 & 68.1 & 7.0 \\
D851 & 217.0 & 4.5 \\
\hline
\end{tabular}


Table 6 Normal stresses $\sigma_{n}$ and shear stresses $\tau$ at/in the diamond-filler alloy interfaces $A_{1}, A_{2}$ and $A_{3}$

\begin{tabular}{|c|c|c|c|c|c|c|}
\hline \multirow[t]{2}{*}{ Grain size } & \multicolumn{2}{|l|}{$A_{1}$} & \multicolumn{2}{|l|}{$A_{2}$} & \multicolumn{2}{|l|}{$A_{3}$} \\
\hline & $\sigma_{n}(\mathrm{MPa})$ & $\tau(\mathrm{MPa})$ & $\sigma_{n}(\mathrm{MPa})$ & $\tau(\mathrm{MPa})$ & $\sigma_{n}(\mathrm{MPa})$ & $\tau(\mathrm{MPa})$ \\
\hline D356 & -633 & 276 & 77 & 686 & -556 & 410 \\
\hline D501 & -363 & 184 & 23 & 406 & -340 & 223 \\
\hline D851 & -211 & 88 & 30 & 227 & -182 & 139 \\
\hline
\end{tabular}

size. Whereas in case of D356 and D501 grains, the bending stress is in the range of the failure strength; in case of D851, the failure strength is lower than the bending torque. The small fracture toughness of diamond leads, in the presence of a critical flaw in combination with corresponding fracture load, to an unstable sudden crack propagation and therefore to a grain fracture. The interaction of bending stress and decreasing failure strength favours the grain fracture for large diamond grains.

The increased failure force for pulled out grits is due to the significantly larger embedded grain area, exhibiting a higher retention force. For comparison: A single Nielectroplated diamond (average diameter: $100 \mu \mathrm{m}$ ), which has $85 \%$ grain protrusion, has a bonding force between 1.5 and $3.0 \mathrm{~N}$ [54]. Compared to the failure forces measured in this work, these values are 2 orders of magnitude lower. The reason for this is that the different retention mechanism, namely mechanical, occurs instead of chemical bonding. For the failure mechanism "grain fracture", it seems that the maximum withstood forces are nearly the same, namely roughly $F_{F, c} \approx 100 \mathrm{~N}$ and $F_{F, n} \approx 150 \mathrm{~N}$, except from those measured for D851 grains brazed with $\mathrm{Cu}$-Sn-based filler alloy. Since for this failure mechanism only the properties of diamond, i.e. strength and fracture toughness, as well as the occurring residual stresses are relevant, it is independent of the used filler alloy. In [55, 56], the residual stresses of brazed diamonds were investigated. It was found that the magnitude is in the same range $(\approx-350 \mathrm{MPa})$ for two filler alloys. In most cases, the failure cutting force for "grain fracture" is lower than the force for "grain pullout". The reason could be the inherent susceptibility of ceramics, including diamond, to tensile stresses because of their inability to plastically deform for stress relief, resulting in a very low fracture toughness $K_{\text {Ic, diamond }}=4-5 \mathrm{MPa} \mathrm{m}^{1 / 2}$ [45]. The critical flaws, provoking stress concentration at their tips, in technical ceramics/(artificial) diamonds are introduced during the production process. In addition, a high brazing temperature introduces defects in the diamond lattice, weakening the diamond. But also a slightly ductile filler alloy reduces the internal stresses due to plastic deformation and creep.

The scratch areas at failure are extremely high for the grain size D851 compared to the other ones. Therefore, these grains can be used for efficient grinding with high depth of cuts, resulting in high material removal. The failure forces for D851 grains are significantly higher, too. The calculation of the ratios $F_{F, c} / A_{\text {scratch }}$ and $F_{F, n} / A_{s c r a t c h}$ allows the direct comparison of the different grain sizes. In the case of diamonds brazed with the Ag-Cu-based filler alloy, both failure mechanisms show a decrease of roughly 3,000 N/ $\mathrm{mm}^{2}$ in the ratio $F_{F, c} / A_{\text {scratch }}$ with increasing grain size. This is concluded because the error is equal for all grain sizes, as can be seen in Fig. $7 \mathrm{c}$. The interpretation of the $F_{F, c} / A_{\text {scratch }}$ and $F_{F, n} / A_{\text {scratch }}$ ratios for the $\mathrm{Cu}-\mathrm{Sn}$-brazed diamonds is similar. The failure mechanism "grain fracture" exhibits a more significant decrease in the ratios with increasing grain size, whereas the $F_{F, c} / A_{\text {scratch }}$ ratio for the failure mechanism "grain pullout" only exhibit a tendency to decrease with increasing grain size. Here, the conclusion is that the grain size strongly influences the pullout; even though the withstood forces are much higher for D851, the ratio is significantly lower. Comparing the filler alloys, it can be stated that the ratios in case of the $\mathrm{Cu}-\mathrm{Sn}$-based filler alloy significantly depend on the applied grain size, whereas it is nearly independent for the $\mathrm{Ag}$-Cu-based one.

The bond strengths of diamond grains are compared to those of block-shaped monocrystalline diamonds, which were determined in $[55,56]$. The filler alloys, the substrate material and the brazing conditions were the same, only the diamond geometry was changed. The diamond grains brazed with the $\mathrm{Cu}-\mathrm{Sn}$-based filler alloy exhibit a bond strength $\tau=(237 \pm 58) \mathrm{MPa}$, whereas the block-shaped ones have $\tau=(199 \pm 18) \mathrm{MPa}$. In case of the Ag-Cu-brazed diamond, the grains have $\tau=(162 \pm 52) \mathrm{MPa}$, whilst the blockshaped ones possess a higher value of $\tau=(248 \pm 124) \mathrm{MPa}$. The reason for the observed difference is the removal of the fillets around the block-shaped ones, losing their supporting effect. On the basis of the bond strength, it is stated that the $\mathrm{Cu}-\mathrm{Sn}$-based filler alloy better prevents the grains from pullout, because it is stronger than the $\mathrm{Ag}$-Cu-based one. This fact can also be seen in the percentages of the failure mechanism "grain pullout" especially for larger grain sizes (compare Figs. 7a and 8a).

\subsection{Cutting characteristics}

The effect of the rake angle on the cutting forces is displayed in Fig. 10a and b. A direct comparison of the 
influence of the rake angle was possible, since the clearance angle was zero for both. Based on the recorded forces, a rake angle of $\gamma \approx-20^{\circ}$ is more favourable to material removal compared to $\gamma \approx-35^{\circ}$, because of the lower material compression during chip formation and of the ease of chip removal. In [35], the same effect of the rake angle on the measured forces was found as well. In machining, a rule of thumb is that a rake angle decrease of $1^{\circ}$ increases the cutting force of about $+1.5 \%$ and vice versa [57]. This fact supports the strong force increase for $\gamma=-35.3^{\circ}$ and the comparably lower one for $\gamma=-19.5^{\circ}$. The cutting and normal forces of a shaped diamond depend linearly on the scratch area until $A_{\text {scratch }} \approx 1,000 \mu \mathrm{m}^{2}$ [36]. This is not contradictory to the results of this work, because if only concerning the forces at small scratch areas, a linear relationship can be established with sufficient accuracy, too. The fitting of the data points with Eq. (1) results mostly in a power of $\approx 0.5$. This means that the increase in force is lower than the increase in scratch area. At small scratch areas the strong increase in force is due to the friction between the contact pair diamond workpiece and ploughing, which is more significant for low-scratch areas, because of the rounding of the cutting edge [37]. The contribution of micro-cutting rise with larger scratch area and therefore the increase in force is attenuated.

\section{Summary and conclusions}

In this work, the failure mechanisms and the cutting characteristics of brazed diamond grains, using different sizes (D356, D501 and D851) and two filler alloys (Ag-Cu-based and $\mathrm{Cu}$-Sn-based), were investigated. The evaluation of the single grain scratching tests gives rise to the following conclusions:

\subsection{Failure mechanisms}

- Small diamond grits mainly fail due to "grain pullout", whereas big grits tend to "grain fracture". The simple mechanical model supports the observed trend.

- The crucial influences are the embedded area (chemical bonding) in combination with the supporting effect of the fillet, the probability of the presence of critical flaws and the bending torque on the diamond during engagement.

- The bond strength of $\mathrm{Cu}-\mathrm{Sn}$-brazed diamonds is $\approx 240 \mathrm{MPa}$ and for the Ag-Cu-brazed ones roughly $160 \mathrm{MPa}$.

\subsection{Cutting characteristics}

- It is concluded that for small scratch areas, the force is mainly determined by rubbing and micro-ploughing; whilst for large scratch areas, the micro-cutting process is main responsible for the increase in force.

- The effect of the rake angle $\gamma$ on the cutting forces is significant, i.e. the larger the negative rake angle the higher the obtained forces.

Acknowledgments The authors would like to thank the Swiss National Science Foundation for the financial support under the grant number 200021-117847. SB is grateful to Dr. H-R Elsener (Laboratory for Joining and Interface Technology, Empa, Duebendorf) for his support in brazing.

\section{References}

1. Machining (1989) Metals handbook, vol 16. American Society for Metals, Materials Park

2. Malkin S, Guo C (2008) Grinding technology, vol XII, 2nd edn. Industrial Press, Inc., New York, p 372

3. Shaw MC (1996) Principles of abrasive processing. Oxford series on advanced manufacturing, vol XVIII. Clarendon, Oxford, p 574 $\mathrm{S}$

4. Burkhard G (2001) Beitrag zur Optimierung von einschichtigen Abrasivwerkzeugen. PhD-Thesis, Eidgenössische Technische Hochschule Zürich ETHZ, Switzerland

5. Burkhard G, Rehsteiner F (2002) High efficiency abrasive tool for honing. CIRP 51(1):271-274

6. Chattopadhyay AK, Chollet L, Hintermann HE (1991) Experimental investigation on induction brazing of diamond with $\mathrm{Ni}-\mathrm{Cr}$ hardfacing alloy under argon atmosphere. J Mater Sci 26 (18):5093-5100

7. Chattopadhyay AK, Chollet L, Hintermann HE (1991) Induction brazing of diamond with Ni-Cr hardfacing alloy under argon atomosphere. Surf CoatTechnol 45(1-3):293-298

8. Hintermann HE, Chattopadhyay AK (1992) New generation superabrasive tool with monolayer configuration. Diamond Relat Mater 1(12):1131-1143

9. Pinto FW (2008) An experimental and numerical approach to investigate the machining performance of engineered grinding tools. PhD thesis, Eidgenössische Technische Hochschule Zürich ETHZ, Switzerland

10. Sung JC, Sung M (2009) The brazing of diamond. Int J Refract Met Hard Mater 27:382-393. doi:10.1016/j.ijrmhm.2008.11.011

11. Aurich JC, Braun O, Warnecke G (2003) Development of a superabrasive grinding wheel with defined grain structure using kinematic simulation. CIRP 52(1):275-280

12. Lee C, Ham J, Song M (2007) The interfacial reaction between diamond grit and Ni-based brazing filler metal. Mater Trans 48 (4):889-891. doi:10.2320/matertrans.48.889

13. Shiue RK, Buljan ST, Eagar TW (1997) Abrasion resistant active braze alloys for metal single layer technology. Sci Technol Weld Join 2(2):71-78

14. Sung CM (1999) Brazed diamond grid: a revolutionary design for diamond saws. Diamond Relat Mater 8(8-9):1540-1543

15. Huang $\mathrm{H}$, Zhu HM, Xu XP (2004) Grinding of granite with three kinds of diamond tools. Key Eng Mater 259-2:146-150

16. Xu JH, Ding WF, Qian F (2007) Shear strength of brazed joint between diamond grains and steel matrix using a Ni-Cr filler alloy. Key Eng Mater 329:501-506. doi:Issn 1013-9826

17. Pinto FW, Vargas GE, Wegener K (2008) Simulation for optimizing grain pattern on engineered grinding tools. CIRP 57(1):353356. doi:10.1016/j.cirp.2008.03.069 
18. Pinto FW, Wegener K, Kuster F, Kiser M (2005) Parameters to evaluate the differences between engineered and conventional grinding tools. 38th CIRP International Seminar of Manufacturing Systems Florianópolis, Brazil

19. Wegener K, Pinto FW, Kuster F, Vargas GE, Transchel R (2010) Simulation zur Optimierung von Schleifwerkzeugen mit definierter Kornanordnung. Diamond Bus 2:28-33

20. Koshy P, Iwasaki A, Elbestawi MA (2003) Surface generation with engineered diamond grinding wheels: insights from simulation. CIRP 52(1):271-274

21. Pinto FW, Wegener K, Kuster F, Wunder S, Kiser M (2005) Model to optimise the grain pattern of grinding discs with controlled positions of the abrasives. 8th CIRP International Workshop on Modeling of Machining Operations Chemnitz, Germany, pp 349359

22. Braun O, Warnecke G, Aurich JC (2005) Simulation-based development of a superabrasive grinding wheel with defined grain structure. In: Transactions of the North American Manufacturing Research Institution of SME 2005, vol 33. Transactions of the North American Manufacturing Research Institution of Sme. Society of Manufacturing Engineers, Dearborn, MI, pp 351358

23. Webster J, Tricard M (2004) Innovations in abrasive products for precision grinding. CIRP 53(2):597-617

24. Aurich JC, Herzenstiel P, Sudermann H, Magg T (2008) Highperformance dry grinding using a grinding wheel with a defined grain pattern. CIRP 57(1):357-362. doi:10.1016/ j.cirp.2008.03.093

25. Hagiwara S, Obikawa T (2002) Evaluation of edge fracture characteristics of diamond grains in stone grinding processes. Mach Sci Technol 6(1):53-66

26. Keen D (1971) Some observations on wear of diamond tools used in piston machining. Wear 17(3):195-208

27. Boadi JK, Yano T, Iseki T (1987) Brazing of pressureless-sintered $\mathrm{SiC}$ using Ag-Cu-Ti alloy. J Mater Sci 22(7):2431-2434. doi:10.1007/bf01082127

28. Hao HQ, Jin ZH, Wang XT (1994) The influence of the brazing conditions on joint strength in $\mathrm{Al}_{2} \mathrm{O}_{3} / \mathrm{Al}_{2} \mathrm{O}_{3}$ bonding. J Mater Sci 29(19):5041-5046

29. Nicholas MG, Mortimer DA, Jones LM, Crispin RM (1990) Someobservations on the wetting and bonding of nitride ceramics. J Mater Sci 25(6):2679-2689

30. Liao YS, Luo SY (1992) Wear characteristics of sintered diamond composite during circular sawing. Wear 157(2):325-337

31. Atkins AG (1999) Scaling laws for elastoplastic fracture. Int J Fract 95(1-4):51-65. doi:10.1023/a:1018683830486

32. Herrmann HJ (1991) Fractures. In: Bunde H, Havlin S (eds) Fractals and disordered systems. Springer, Berlin, pp 175-205

33. Bredell LJ, Prins JF (1982) Microcutting of steel, copper and zinc - a comparative study. Wear 82(1):127-135

34. Bredell LJ, Prins JF (1982) Microcutting of steel using pyramidal diamonds with different apex angles. Wear 76(2):177-187

35. Ohbuchi Y, Matsuo T (1991) Force and chip formation on singlegrit orthogonal cutting with shaped $\mathrm{cBN}$ and diamond grains. CIRP 40(1):327-330

36. Matsuo T, Toyoura S, Oshima E, Ohbuchi Y (1989) Effect of grain shape on cutting force in superabrasive single-grit tests. CIRP 38 (1):323-326
37. Brinksmeier E, Giwerzew A (2003) Chip formation mechanisms in grinding at low speeds. CIRP 52(1):253-258

38. Akono AT, Ulm FJ (2011) Scratch test model for the determination of fracture toughness. Eng Fract Mech 78(2):334-342. doi:10.1016/j.engfracmech.2010.09.017

39. Ulm FJ, James S (2011) The scratch test for strength and fracture toughness determination of oil well cements cured at high temperature and pressure. Cem Concr Res 41(9):942-946. doi:10.1016/ j.cemconres.2011.04.014

40. Akono AT, Reis PM, Ulm FJ (2011) Scratching as a fracture process: from butter to steel. Phys Rev Lett 106(20). doi:10.1103/PhysRevLett.106.204302

41. Mizuhara H, Huebel E, Oyama T (1989) High-reliability joining of ceramic to metal. Am Ceram Soc Bull 68(9):1591-1599

42. Klotz UE, Liu CL, Khalid FA, Elsener HR (2008) Influence of brazing parameters and alloy composition on interface morphology of brazed diamond. Mater Sci Eng A 495:265-270

43. Field JE (1979) The properties of diamond. Academic, London

44. Field JE (1992) Strength, fracture and erosion properties of diamond. In: Field JE (ed) The properties of natural and synthetic diamond. Academic, London, pp 473-513

45. Field JE (1994) Cleavage, fracture and tensile strength of diamond. In: Davies G (ed) Properties and growth of diamond. INSPEC, London, pp 36-51

46. Ikawa N, Shimada S, Ono T (1976) Microstrength of diamond. Technol Rep Osaka Univ 26(1276-1307):245-254

47. Kizikov ED, Kebko VP (1987) Microadditions to alloys of the system Cu-Sn-Ti. Met Sci Heat Treat 29(1-2):68-71

48. Kizikov ED, Lavrinenko IA (1975) Investigations of Cu-Sn-Ti alloys used for bonding diamond abrasive tools. Met Sci Heat Treat 17(1-2):61-65

49. Wegst C, Wegst M (2007) Nachschlagewerk Stahlschüssel. Verlag Stahlschüssel Wegst GmbH, Marbach

50. Luo SY, Liao YS (1995) Study of the behavoir of diamond sawblades in stone processing. J Mater Process Technol 51(1-4):296308

51. Feng Z, Field JE (1989) Dynamic strengths of diamond grits. Ind Diam Rev 3:104-108

52. Field JE, Freeman CJ (1981) Strength and fracture properties of diamond. Philos Mag A 43(3):595-618

53. Pugno NM (2005) The nanoscale strength of ultra nano crystalline diamond. Rev Adv Mater Sci 10(2):156-160

54. Suzuki T, Mitsui T, Fujino T, Kato M, Satake Y, Saito H, Kobayashi S (2009) Development of CNT-coated diamond grains using selfassembly techniques for improving electroplated diamond tools. In: Kuriyagawa T, Zhou L, Yan J, Yoshihara N (eds) Advances in Abrasive Technology XI, vol 389-390. Key Engineering Materials. pp 72-76

55. Buhl S, Leinenbach C, Spolenak R, Wegener K (2010) Influence of the brazing parameters on microstructure, residual stresses and shear strength of diamond-metal joints. J Mater Sci 45(16):4358 4368. doi:10.1007/s10853-010-4260-7

56. Buhl S, Leinenbach C, Spolenak R, Wegener K (2012) Microstructure, residual stresses and shear strength of diamond-steeljoints brazed with a $\mathrm{Cu}-\mathrm{Sn}$-based active filler alloy. Int J Refract Met Hard Mater 30(1):16-24

57. Klocke F, König W (2008) Band 1: Drehen, Fräsen, Bohren. Fertigungsverfahren. VDI-Verlag, Düsseldorf 